\title{
Stomatal Conductance of Lysimeter-grown Asian Pear Trees before and during Soil Moisture Deficits
}

\author{
A. Richard Renquist ${ }^{1}$ \\ Orchard Mesa Research Center, Colorado State University, Grand Junction, CO 81503
}

Horst W. Caspari' ${ }^{2}$, M. Hossein Behboudian, and David J. Chalmers ${ }^{3}$
Department of Plant Science, Massey University, Palmerston North, New Zealand

Additional index words. Pyrus serotina, nashi, Japanese pear, lysimetry, transpiration, heat-pulse technique, porometry

\begin{abstract}
Stomatal conductance $\left(g_{\mathrm{s}}\right)$ of 'Hosui' Asian pear (Pyrus serotina Rehder) trees growing in lysimeters was characterized for trees in well-watered soil and after brief water deficit. The measures of water status used to interpret $g_{\mathrm{s}}$ data were soil-water content, leaf water potential $\left(\psi_{1}\right)$, and instantaneous water use (trunk sap flow by the compensation heat-pulse technique). The diurnal course and range of $g_{\mathrm{s}}$ values of well-irrigated Asian pear trees were similar to those reported for other tree fruit crops. Soil moisture at the end of a midsummer deficit period was $60 \%$ of lysimeter pot capacity, and diurnal $\psi_{1}$ reflected this deficit predawn and in the late afternoon compared to well-irrigated trees. The $g_{\mathrm{s}}$ was sensitive to deficit irrigation during more of the day than $\psi$, with $g_{\mathrm{s}}$ values $<3 \mathrm{~mm} \cdot \mathrm{s}^{-1}$ for most of the day; these were less than half the conductances of well-irrigated trees. The reduction of $g_{\mathrm{s}}$ in response to a given soil-water deficit was not as great on days with lower evaporative demand. After a water deficit, $g_{\mathrm{s}}$ recovered to predeficit values only gradually over 2 to 3 days. The low $g_{s}$ of trees in dry soil was the apparent cause of reduced transpiration, measured by trunk sap flow, and reduced responsiveness of sap flow to fluctuations in net radiation.
\end{abstract}

Asian pears, also known as nashi in the Pacific Rim, are an important new crop in New Zealand (Caspari et al., 1993a). Information on their irrigation management is needed, and research has centered around a drainage lysimeter facility constructed at Massey Univ. in 1987. Several aspects of Asian pear water relations have been studied, including the role of stomata.

Aerodynamically rough, well-ventilated canopies such as forests or orchards are closely coupled to their environment. Consequently, a change in canopy conductance brought about by a change in stomatal conductance $\left(g_{s}\right)$ can therefore cause an almostproportional change in transpiration (Jarvis and McNaughton, 1986). Jones and Higgs (1989) used a model involving air temperature, vapor-pressure deficit (VPD), and irradiance to predict apple (Malus domestica Borkh.) leaf $g_{\mathrm{s}}$. While $32 \%$ to $62 \%$ of $g_{\mathrm{s}}$ variance could be explained, the model fit could be significantly improved by including the soil-moisture deficit.

Reduced stomatal aperture due to soil-water deficit has been observed in many studies. When irrigation of potted peach [Prunus persica (L.) Batsch] seedlings was stopped, there was no obvious effect on stomata for the first 3 days (Tan and Buttery, 1982). Thereafter, $g_{\text {s }}$ declined rapidly, closely following the decline in available soil moisture. Similar responses of stomata to reduced soil water have been reported for apple (Higgs and Jones, 1990), apple and sour cherry (P. cerasus L.) (Flore et al., 1985), and grape (Vitis vinifera L.) (Downton et al., 1987).

The objective of this study was to characterize aspects of stomatal behavior of Asian pear in well-watered soil and after brief

Received for publication 19 Oct. 1993. Accepted for publication 13 Apr. 1994. Mention of trade names does not constitute a guarantee or warranty of the products by Massey Univ. nor does it imply endorsement of similar commercial products. We gratefully acknowledge the support of W.R.N. Edwards for installing and maintaining the heat-pulse equipment. The cost of publishing this paper was defrayed in part by the payment of page charges. Under postal regulations, this paper therefore must be hereby marked advertisement solely to indicate this fact.

${ }^{1}$ Visiting scientist at Massey Univ. funded by Colorado Agricultural Experiment Station project 138. To whom reprint requests should be addressed at Massey Univ. ${ }^{2}$ Visiting scientist from Institut für Obstbau und Gemüsebau, Rheinische FriedrichWilhelms-Universität Bonn, Bonn, Germany. Supported by a grant from Gottlieb Daimler- und Karl Benz-Stiftung, Ladenburg, Germany.

${ }^{3}$ Professor. Current address: 13 Valleyside Dr., Crafers, SA 5152, Australia. water deficit. Diurnal $g_{\mathrm{s}}$ patterns are discussed in relation to leaf water potential $\left(\psi_{1}\right)$ and transpiration as measured by the compensation heat-pulse technique.

\section{Materials and Methods}

Twelve fourth-season 'Hosui' Asian pear trees on Pyrus serotina seedling rootstock were grown in 1.0-m-diameter, 1.2 -m-deep lysimeters located in a 1.1-ha block of Asian pear trees in the orchards of Massey Univ., Palmerston North, New Zealand (lat. $40.2^{\circ} \mathrm{S}$, long. $\left.175.4^{\circ} \mathrm{E}\right)$. The 12 drainage-type lysimeters consisted of steel cylinders tapered to a point for water collection, each within a concrete sleeve. Spacing was $1.2 \mathrm{~m}$ between trees and 5 $\mathrm{m}$ between rows. Lysimeters were filled with sand similar in texture to that of Manawatu fine sandy loam in the surrounding orchard. Details were provided by Chalmers et al. (1992). Trees were trained onto a Tatura trellis (Chalmers et al., 1978).

Irrigation water and nutrients were supplied to each lysimeter at 16 liters $\cdot \mathrm{h}^{-1}$ through eight drippers controlled by the same computerized system that measured drainage and monitored environmental sensors. Lysimeters had flexible covers that fastened around the tree trunk to keep the rain out. Water use was determined indirectly using a conservation of water equation (Chalmers et al., 1992). Irrigation amount and drainage were measured directly. Changes in soil-water storage were calculated for each lysimeter from twice-weekly neutron hydroprobe (model 503DR; CPN Corp., Martinez, Calif.) readings of water content made at 0.2-m intervals, 0.2 to $1.0 \mathrm{~m}$ beneath the sand medium surface. During drying cycles, soil moisture was measured more frequently and at 0.1-m-deep intervals. Hydroprobe calibration and converting soilwater storage to liters have been reported (Chalmers et al., 1992).

All 12 trees were irrigated equally and kept above pot capacity from mid-September 1990 until the end of May 1991, except for three several-day drying cycles designated DC-1, DC-2, and DC3 (Caspari et al., 1993a). The cycles referred to here are DC-2, from 14 to 23 Jan. 1991 (99 to 108 days after full bloom), and DC-3, from 28 Feb. to 13 Mar. 1991 (144 to 157 days after full bloom). Pot capacity is defined as the soil-moisture content when drainage has just ceased after wetting. Deficits were maintained only briefly, so 
as not to prevent trees from filling their allotted trellis space during this fourth season. Class A pan evaporation was measured within $1 \mathrm{~km}$ of the lysimeter site.

Diurnal $\psi_{1}$ and $g_{\mathrm{s}}$ were measured on days when all trees were well irrigated and on days during drying cycles. A pressure chamber (Soilmoisture Equipment Corp., Santa Barbara, Calif.) was used for measuring $\psi_{1}$, and a transit-time porometer $(\mathrm{Mk} 3$; Delta-T Devices, Cambridge, U.K.) was the primary instrument for measuring $g_{s}$. Asian pear trees were confirmed to be hypostomatous by making a silicone rubber impression. Pretesting in December indicated that shaded and young (light-green) leaves should not be used to measure $g_{s}$. The $\psi_{1}$ measurements, on the other hand, were more consistent if shaded leaves were used. Each mean $\psi_{1}$ value for a given irrigation regime included at least 10 leaves. Mean $g_{\mathrm{s}}$ values included at least 6 readings and usually 12 or more. Seasonal $\psi_{1}$ measurements and meteorological data were reported previously (Caspari et al., 1993a).

In addition to the lysimeter method, the compensation heatpulse technique (Swanson and Whitfield, 1981) was used to measure transpiration of two adjacent trees from 18 Jan. to 13 Mar. 1991 from the rate of sap movement upward through the stem. Thermistor probes were installed 5 and $15 \mathrm{~mm}$ below the cambium. Details were reported earlier (Caspari et al., 1993a). The heat-pulse data were recorded by a Custom Heat-pulse Logger (HortResearch, Palmerston North). Sap flux was derived from the corrected sap velocities according to Edwards and Warwick (1984).

\section{Results and Discussion}

Diurnal $g_{\mathrm{s}}$ of well-watered Asian pear trees for 3 days in Summer and Fall 1991 are given in Fig. 1. Generally, $g_{\mathrm{s}}$ increased until midmorning and remained relatively high until late afternoon. Stomata closed rapidly during the evening in response to falling light levels. Afternoon $g_{\mathrm{s}}$ patterns were more variable on the two dates after the crop's removal in early February, although lower evaporative demand and other factors could also have affected this variability. Similar diurnal $g_{\mathrm{s}}$ patterns were also observed during the 1991-92 season, although all $g_{\mathrm{s}}$ values were $<8 \mathrm{~mm} \cdot \mathrm{s}^{-1}$ (Caspari, 1993). When measurements under low light intensity are excluded, the $g_{\mathrm{s}}$ of well-watered trees was 4 to 10 $\mathrm{mm} \cdot \mathrm{s}^{-1}$. The $g_{\mathrm{s}}$ pattern and range agree well with those reported for other fruit crops (Jones et al., 1985; Lakso, 1985). Research on some tree fruit crops did not find a primary link between $\mathrm{g}_{\mathrm{s}}$ and leaf water status, a result that suggests $\psi_{1}$ is secondary to environmental factors such as light, $\mathrm{CO}_{2}$ concentration, and VPD (Syvertsen, 1985). However, Higgins et al. (1992) reported that stomata of greenhouse-grown Asian pear trees were comparatively unresponsive to VPD changes, so that transpiration increased linearly with VPD at 0.7 to $3.8 \mathrm{kPa}$. This result was supported by field measurements of transpiration (trunk sap flow) and net radiation of Asian pear trees (Caspari, 1993). Daily sap flow for well-watered trees closely followed the net radiation pattern, which would not be expected on warm sunny days if stomata were able to control transpiration via rapid response to VPD, net radiation, or leaf temperature. This result suggests that, even with adequate soil moisture, Asian pear trees may become highly water stressed in a hot arid climate. Asian pear trees are able to grow well in such climates, however, a result that raises the question of whether transitory leaf water deficits larger than those that occurred here could result in stomatal regulation of transpiration.

Transit-time porometer readings in this lysimeter study were 1 to $10 \mathrm{~mm} \cdot \mathrm{s}^{-1}$, a range at which the instrument is most reliable. For characterizing stomatal behavior of a species in response to moisture deficit, of most interest are relative $g_{\mathrm{s}}$ values among treatments. To have a better sense of absolute values for Asian pear, we also directly compared the transit-time porometer with a steady-

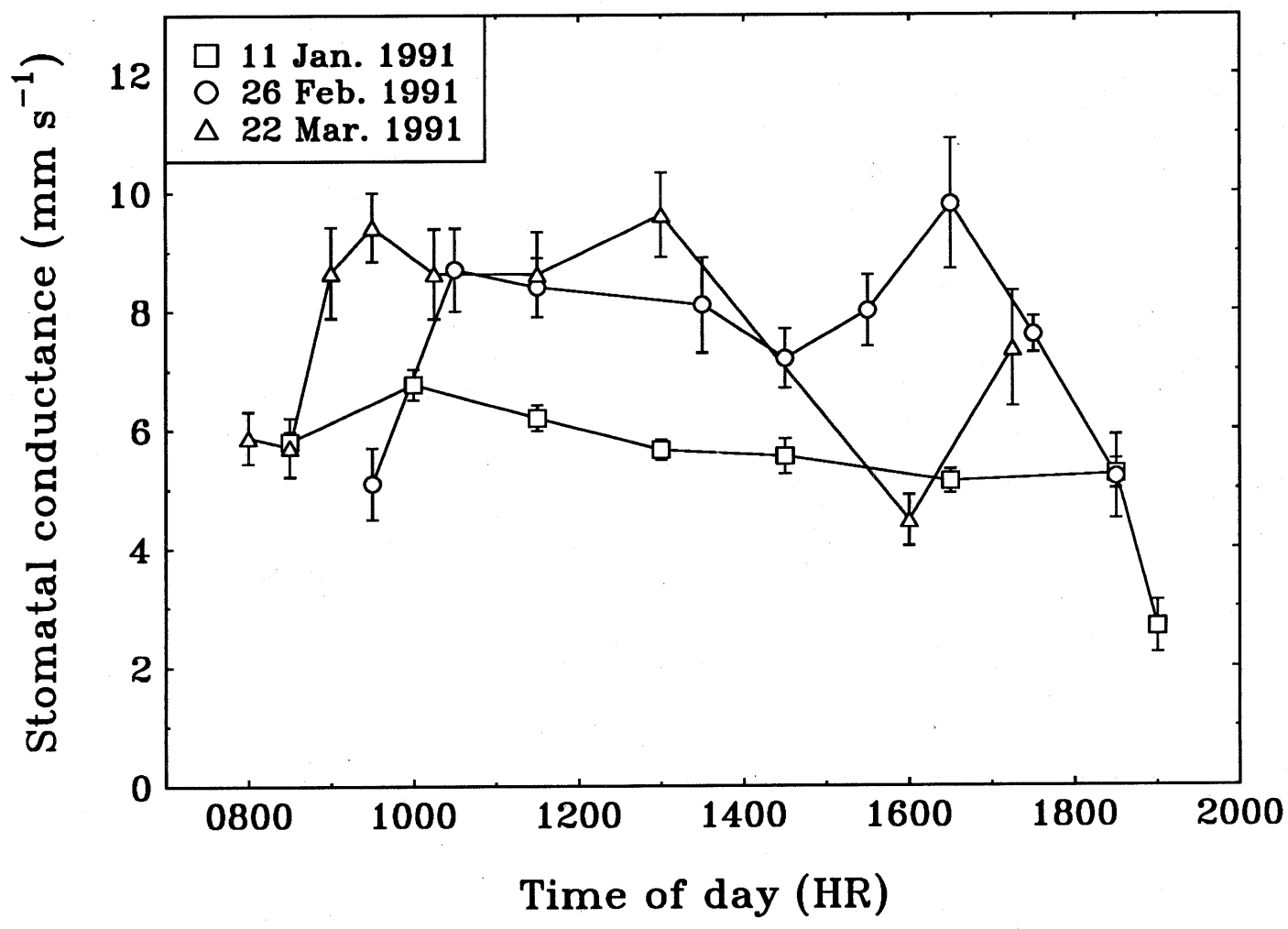

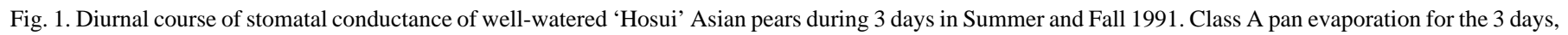
in order of occurrence, was 5.3, 4.0, and $3.2 \mathrm{~mm}$. Bars represent twice the SE of the means. 
state porometer (LI-1600; LI-COR, Lincoln, Neb.). Figure 2 shows that $g_{\text {s }}$ values were consistently higher for the transit-time unit, although the differences were not large from 4 to $10 \mathrm{~mm} \cdot \mathrm{s}^{-1}$. Each type of porometer tends to lack sensitivity at one end of the $g_{\mathrm{s}}$ range, such that $g_{\mathrm{s}}$ values of 1 to $3 \mathrm{~mm} \cdot \mathrm{s}^{-1}$ (nearly closed stomata) are best measured with a transit-time unit, and high conductances are best measured with a steady-state unit (Jones, 1983). There are theoretical reasons for greater trust in the accuracy of a steady-state unit (Bell and Squire, 1981; Pearcy et al., 1989), but the comparison in Fig. 2 enhanced our confidence in the transit-time unit for measuring $g_{\mathrm{s}}$ over the range of our data. However, using the transittime unit on one occasion gave 'Hosui' trees growing in the field $g_{\mathrm{s}}$ values as high as $22 \mathrm{~mm} \cdot \mathrm{s}^{-1}$ (data not shown). Such high $g_{\mathrm{s}}$ values would need to be verified with a steady-state unit.

Reducing the soil-water storage by withholding irrigation for 10 days increased plant moisture stress and markedly decreased $g$, during the final days. At the end of DC-2 (14 to 23 Jan. 1991), soil moisture had fallen to $60 \%$ of pot capacity. Water-stressed trees on $23 \mathrm{Jan}$. had a $0.2 \mathrm{MPa}$ lower predawn $\psi_{1}$ than at the start of DC-2 (Caspari et al., 1993a). The $\psi_{1}$ of stressed trees also declined 0.3 $\mathrm{MPa}$ more during the morning and recovered more slowly during late afternoon (at $1730 \mathrm{HR}, \psi_{1}$ was $1.0 \mathrm{MPa}$ lower in stressed than in well-watered trees). While data were from different, but meteorologically similar, days (both with $6 \mathrm{~mm}$ pan evaporation), it is reasonable to conclude that $\psi_{1}$ measured before dawn and/or in the late afternoon is a good indicator of Asian pear water deficit. Early morning $g_{\mathrm{s}}$ values on 23 Jan. were similar to those of well-watered trees, but then declined rapidly and reached a minimum before noon (Fig. 3b). The $g_{\mathrm{s}}$ recovered slightly during the afternoon, but remained much below values for well-watered plants; $g_{\mathrm{s}}$ was $<3$ $\mathrm{mm} \cdot \mathrm{s}^{-1}$ for most of the day, about half that of the same trees before irrigation was withheld. This distinct difference shows that $g_{\mathrm{s}}$ is also a good indicator of water deficit in Asian pear, and for more hours during the day than $\psi_{1}$. The sensitivity of Asian pear $g_{\mathrm{s}}$ to soil moisture is similar to findings with peach (Tan and Buttery, 1982), apple (Flore et at., 1985; Higgs and Jones, 1990; Lakso, 1985), cherry (Flore et al., 1985), and grape (Downton et al., 1987). Based on findings with other fruit crops (Lakso, 1985), the degree of reduced $g_{\mathrm{s}}$ in this study was possibly enough to reduce photosynthetic rate.

Caspari (1993) has compared sap flow rates for well-watered Asian pear trees with those in drier soil during DC-2 and DC-3. While the minimum soil-water levels were both $\approx 60 \%$ of pot capacity, the transpiration decline was greater during DC-2, when evaporative demand was higher. He found that, in well-watered trees, daily sap flow closely followed the pattern of incoming solar and/or net radiation, such that sap flow declined during cloud passage. The diurnal curve for net radiation, while not shown here, can therefore be inferred from Fig. 3 a (moist soil). In contrast, sap flow rate on 23 Jan. (dry soil) decoupled from net radiation and in the afternoon was quite unresponsive to cloud passage. This decoupling was less apparent during DC-3 (Caspari, 1993), when evaporative demand was lower (3.2 vs. $6 \mathrm{~mm}$ pan evaporation). This relationship between solar radiation, sap flow, and $g_{\mathrm{s}}$ was demonstrated in more detail the following year (Caspari et al., 1993b). Partial stomatal closure in response to the combination of dry soil and high evaporative demand (Fig. 3b) was the apparent cause of the $36 \%$ reduction in transpiration on 23 Jan. vs. 18 Jan. (dry vs. moist, Fig. 3a).

When soil water was restored after the drying cycles, $g_{\mathrm{s}}$ gradually recovered to prestress values. This was examined in more detail at the end of DC-3, when four trees were returned to full irrigation on each of 3 consecutive days. On 14 Mar., mean midday $g_{\mathrm{s}}$ was $5.3 \mathrm{~mm} \cdot \mathrm{s}^{-1}$ on trees rewatered $11 \mathrm{Mar} ., 4.0 \mathrm{~mm} \cdot \mathrm{s}^{-1}$ on those irrigated $12 \mathrm{Mar}$., and $2.4 \mathrm{~mm} \cdot \mathrm{s}^{-1}$ on those rewatered 13 Mar. A parallel response in transpiration occurred after DC-2, when trunk

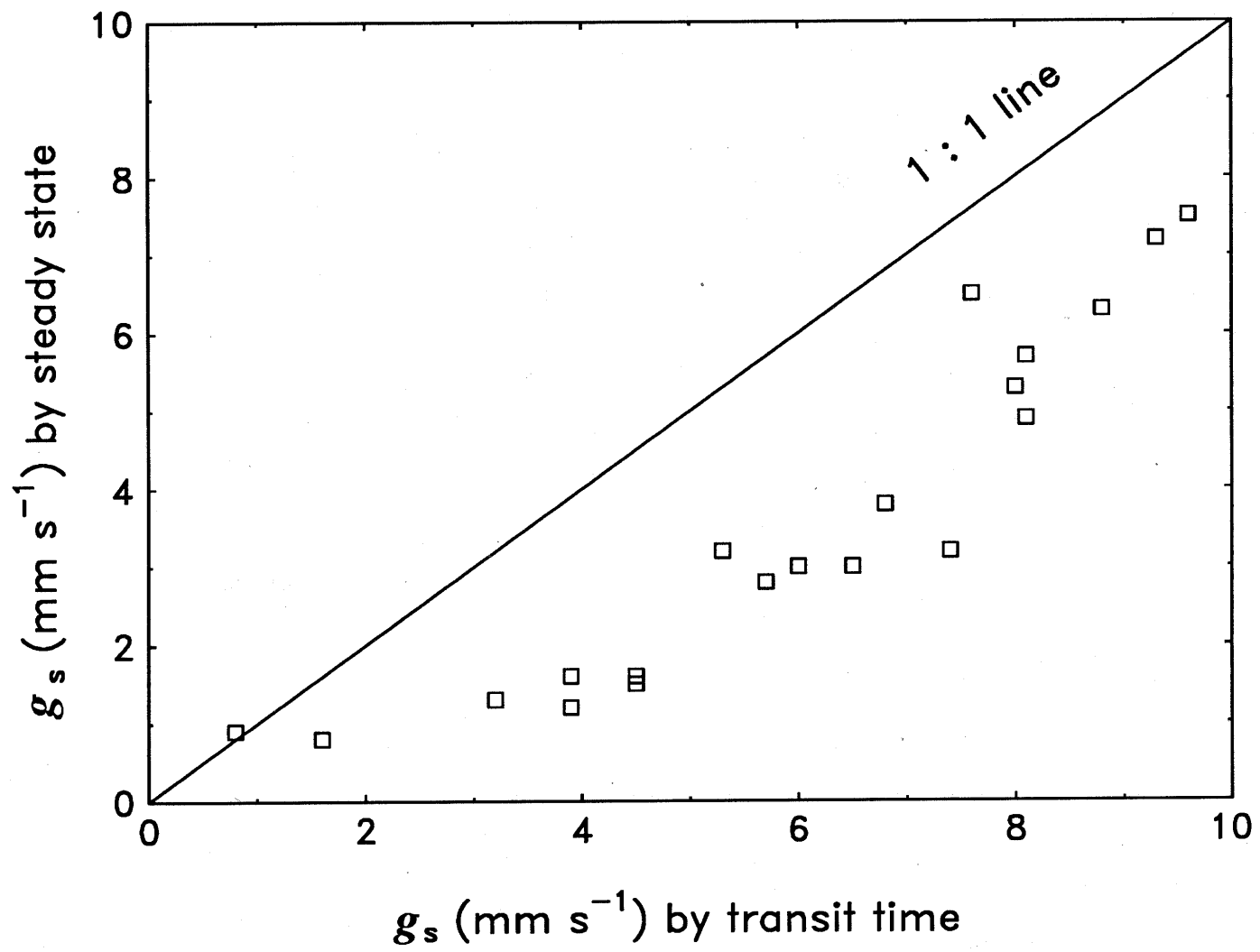

Fig. 2. Stomatal conductance $\left(g_{\mathrm{s}}\right)$ of identical leaves of 'Hosui' Asian pear trees as measured with a transit-time and a steady-state porometer. 


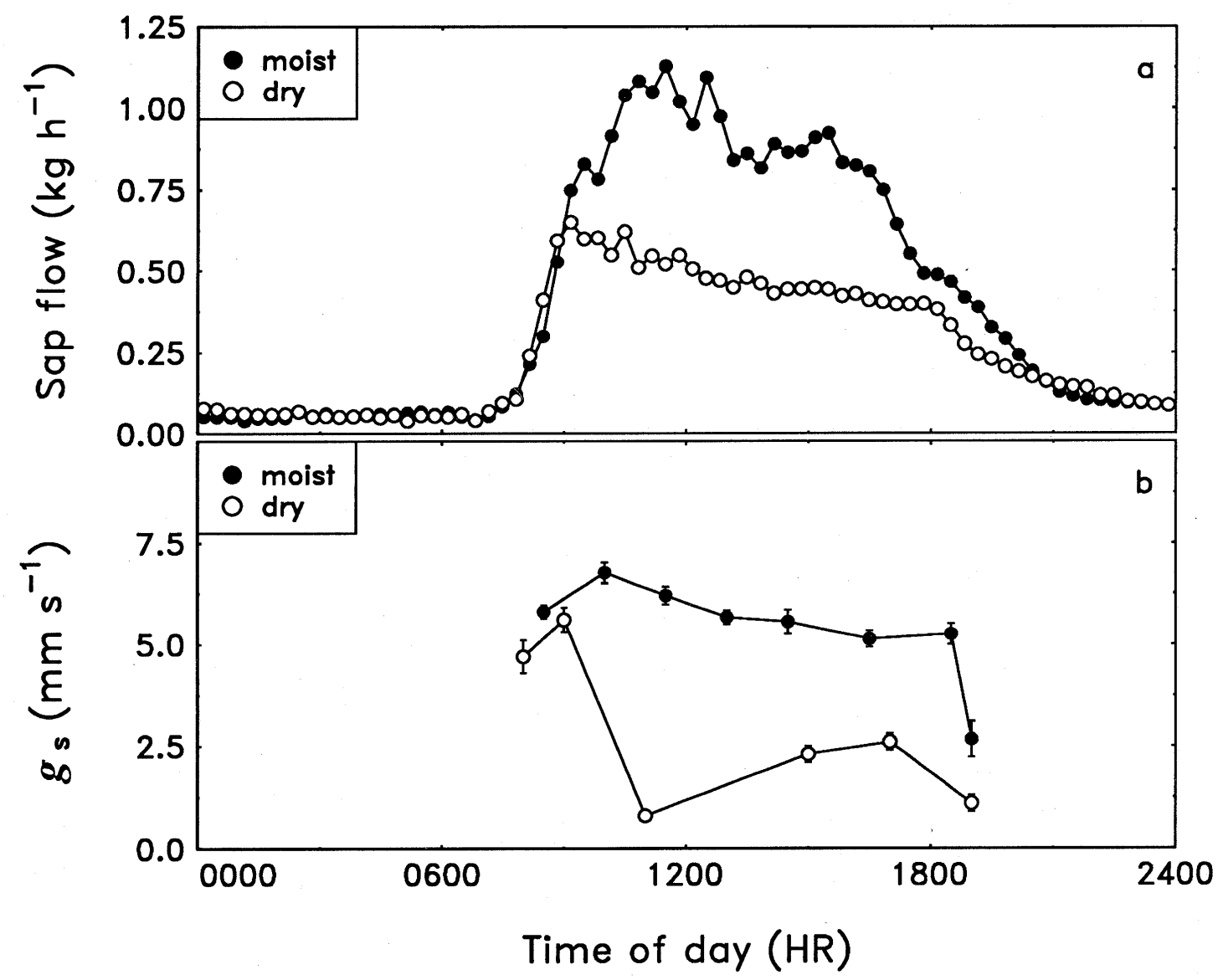

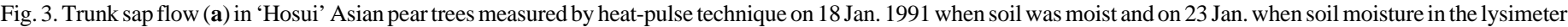
had depleted to $58 \%$ of pot capacity (dry), and mean stomatal conductance (b) on 11 Jan. 1991 (moist) and 23 Jan. (dry). Bars represent twice the SE of the means.

sap flow recovered gradually over 4 to 5 days (Caspari et al., 1993a). These findings are similar to past reports of fruit tree $g_{\mathrm{s}}$ responses during recovery from water deficit. Peach tree $g_{\mathrm{s}}$ rose for several days after rewatering (Tan and Buttery, 1982), and apple and cherry trees required 2 to 3 days for $g_{\mathrm{s}}$ to recover fully (Flore et al., 1985).

Overall, these data indicate that, even in the relatively low evaporative demand climate of New Zealand, stomata can play an active role in controlling transpiration in Asian pears when soil moisture is low. Under well-watered conditions, $g_{s}$ daily course and range were similar to those described for other fruit trees.

\section{Literature Cited}

Bell, C.J. and G.R. Squire. 1981. Comparative measurements with two water vapour diffusion porometers (dynamic and steady-state). J. Expt. Bot. 32:1143-1156.

Caspari, H.W. 1993. The effect of water deficits on the water balance and water relations of Asian pear trees (Pyrus serotina Rehd., cv. Hosui) growing in lysimeters. PhD diss. Rheinische Friedrich-Wilhelms-Universität Bonn, Germany.

Caspari, H.W., M.H. Behboudian, D.J. Chalmers, and A.R. Renquist. 1993a. Pattern of seasonal water use of Asian pears determined by lysimeters and the heat-pulse technique. J. Amer. Soc. Hort. Sci. 118:562-569.

Caspari, H.W., S.R. Green, and W.R.N. Edwards. 1993b. Transpiration of wellwatered and water-stressed Asian pear trees as determined by lysimetry, heat-pulse, and estimated by a Penman-Monteith model. Agr. For. Meteorol. 67:13-27.

Chalmers, D.J., P.K. Andrews, K.M. Harris, E.A. Cameron, and H.W. Caspari. 1992. Performance of drainage lysimeters for the evaluation of water use by Asian pears. HortScience 27:263-265.

Chalmers, D.J., B. van den Ende, and L. van Heek. 1978. Productivity and mechanization of the Tatura trellis orchard. HortScience 13:517-521.

Downton, W.J.S., W.J.R. Grant, and B.R. Loveys. 1987. Diurnal changes in the photosynthesis of field-grown grape vines. New Phytol. 105:71-80.

Edwards, W.R.N. and N.W.M. Warwick. 1984. Transpiration from a kiwifruit vine as estimated by the heat pulse technique and the Penman-Monteith equation. N.Z. J. Agr. Res. 27:537-543.

Flore, J.A., A.N. Lakso, and J.W. Moon. 1985. The effect of water stress and vapor pressure gradient on stomatal conductance, water use efficiency, and photosynthesis of fruit crops. Acta Hort. 171:207-218.

Higgins, S.S., F.E. Larsen, R.B. Bendel, G.K. Radamaker, J.H. Bassman, W.R. Bidlake, and A. Al Wir. 1992. Comparative gas exchange characteristics of potted, glasshouse-grown almond, apple, fig, grape, olive, peach and Asian pear. Scientia Hort. 52:313-329.

Higgs, K.H. and H.G. Jones. 1990. Response of apple rootstocks to irrigation in south-east England. J. Hort. Sci. 65:129-141.

Jarvis, P.G. and K.G. McNaughton. 1986. Stomatal control of transpiration: Scaling up from leaf to region. Adv. Ecol. Res. 15:1-49.

Jones, H.G. 1983. Plants and microclimate. Cambridge Univ. Press, Cambridge, U.K.

Jones, H.G. and K.H. Higgs. 1989. Empirical models of the conductance of leaves in apple orchards. Plant Cell Environ. 12:301-308.

Jones, H.G., A.N. Lakso, and J.P. Syvertsen. 1985. Physiological control of water status in temperate and subtropical fruit trees. Hort. Rev. 7:301-344.

Lakso, A.N. 1985. The effects of water stress on physiological processes in fruit crops. Acta Hort. 171:275-290.

Pearcy, R.W., E.-D. Schulze, and R. Zimmermann. 1989. Measurement of transpiration and leaf conductance, p. 137-160. In: R.W. Pearcy, J.R. Ehleringer, H.A. Mooney, and P.W. Rundel (eds.). Plant physiological ecology: Field methods and instrumentation. Chapman and Hall, London.

Swanson, R.H. and D.W.A. Whitfield. 1981. A numerical analysis of heat pulse velocity theory and practice. J. Expt. Bot. 32:221-239.

Syvertsen, J.P. 1985. Integration of water stress in fruit trees. HortScience 20:1039 1043.

Tan, C.S. and B.R. Buttery. 1982. The effect of soil moisture stress to various fractions of the root system on transpiration, photosynthesis, and internal water relations of peach seedlings. J. Amer. Soc. Hort. Sci. 107:845-849. 